количество эмоций, внимания и сочувствия в сторону пациента и, в том числе, найти силы и желание для предупреждения граждан о правилах поведения и этики, принимая их за само собой разумеющееся, данное.

Это и становится отправной точкой возникновения недовольства и жалоб со стороны посетителей, которые упрекают медицинских работников в равнодушии и бестактности, приводя к ответному формированию халатного и безнравственного поведения, которое, в свою очередь, тянет за собой цепочку последствий, представляющих собой нарушения собственного и чужого покоя, в плоть до осложнений у пациентов, проходящих лечение, либо обратившихся за помощью и консультацией. Всё вышеперечисленное играет значительную роль в рассматриваемой нами проблеме о несоблюдении гражданами правил, установленных на территории лечебно-профилактических учреждений.

$$
* * *
$$

1. Гусейнов А. А. Этика // Новая философская энциклопедия / Ин-т философии РАН; Нац. обществ.науч. фонд; Предс. научно-ред. совета В. С. Стёпин, заместители предс.: А. А. Гусейнов, Г. Ю. Семигин, уч. секр. А. П. Огурцов. - 2-е изд., испр. и допол. - М.: Мысль, 2010. — ISBN 978-5244-01115-9.)

2. Брико Н. И., Зуева Л. П., Покровский В. И. и др.: Эпидемиология: Учебник. Т.1. - М.: ООО «Издательство «Медицинское информационное агентство», 2013. - 832 с.

3. Ермолаева Е.В., Павлова Л.А. Медицинская профессия: требования современного общества // Общество и здоровье: современное состояние и тенденции развития. М., 2013. С. 369-375

4. Всемирная организация здравоохранения. Устав ВОЗ. Всемирная организация здравоохранения. Дата обращения: 23.05.2021.

\title{
Бачал Д.В., Бирюкова Н.В. \\ Культура питания и гигиенического поведения среди подростков, их роль в появлении акне
}

ФГАОУ ВО Первый МГМУ имени И.М. Сеченова Минздрава России (Сеченовский

Университет)

(Россия, Москва)

doi: $10.18411 / \mathrm{j}-06-2021-02$

\section{Аннотация}

В процессе изучения научной литературы и патентной документации была выявлена актуальная в настоящее время проблемы питания и гигиенического поведения среди подростков, являющееся приоритетной проблемой при возникновении распространенного заболевания - акне.

Ключевые слова: акне, угревая болезнь, диета.

\section{Abstract}

In the process of studying scientific literature and patent documentation, the global of the problem of nutrition and hygienic behavior among adolescents was revealed, on the basis of which a common disease arises - acne.

Keywords: acne, acne disease, diet.

\section{Актуальность}

Акне - это очень распространенное поражение кожи, которое влияет на качество жизни, даже легкие формы акне могут вызвать тяжелые психологические проблемы. Люди с угревой болезнью имеют чувство неполноценности, склонны к депрессиям и раздражительны; особенно ярко эти симптомы проявляются у детей в подростковом возрасте, когда отношение к своей внешности очень критично, поэтому проблема 
данной болезни социально значима и распространена в обществе. Она встречается у $85 \%$ юношей и девушек в возрастной категории от 12 до 24 лет, у 10\% сохраняется до 45 лет [1].

Данная проблема была актуальна и в прошлом, ещё древнегреческие врачи распознавали это заболевание. Аристотель и Гиппократ в своих трудах подробно описывают симптомы, не оставляя сомнений о распространенности акне. Со времен Римской империи появляются первые сообщения об использовании каких-либо лекарственных средств. Предполагалось, что, использовав серу, горячие ванны и минеральную воду можно очистить кожу. В Древнем Египте для лечебных и косметических целей широко использовались пилинги. На протяжении веков, как метод лечения, была распространена диета с исключением самых разных продуктов.

Целью данной работы является изучение научной литературы и патентной документации, позволяющей оценить роль питания и гигиены подростков в развитии акне.

Материалы и методы: для достижения поставленной цели использовался мониторинг научных статей, контент-анализ, структурно-логический, сравнительный и системный методы.

\section{Результаты и обсуждения}

На развитие угревой болезни влияет состояние ЖКТ (желудочно - кишечного тракта). У 50-70\% пациентов с акне были выявлены клинические и гистологические признаки гастрита, у 60\% - дисбактериоз, у 30\% - патологические состояния слизистой оболочки тощей кишки. Была установлена зависимость локализации высыпаний от поражения желудочно-кишечного тракта [5]:
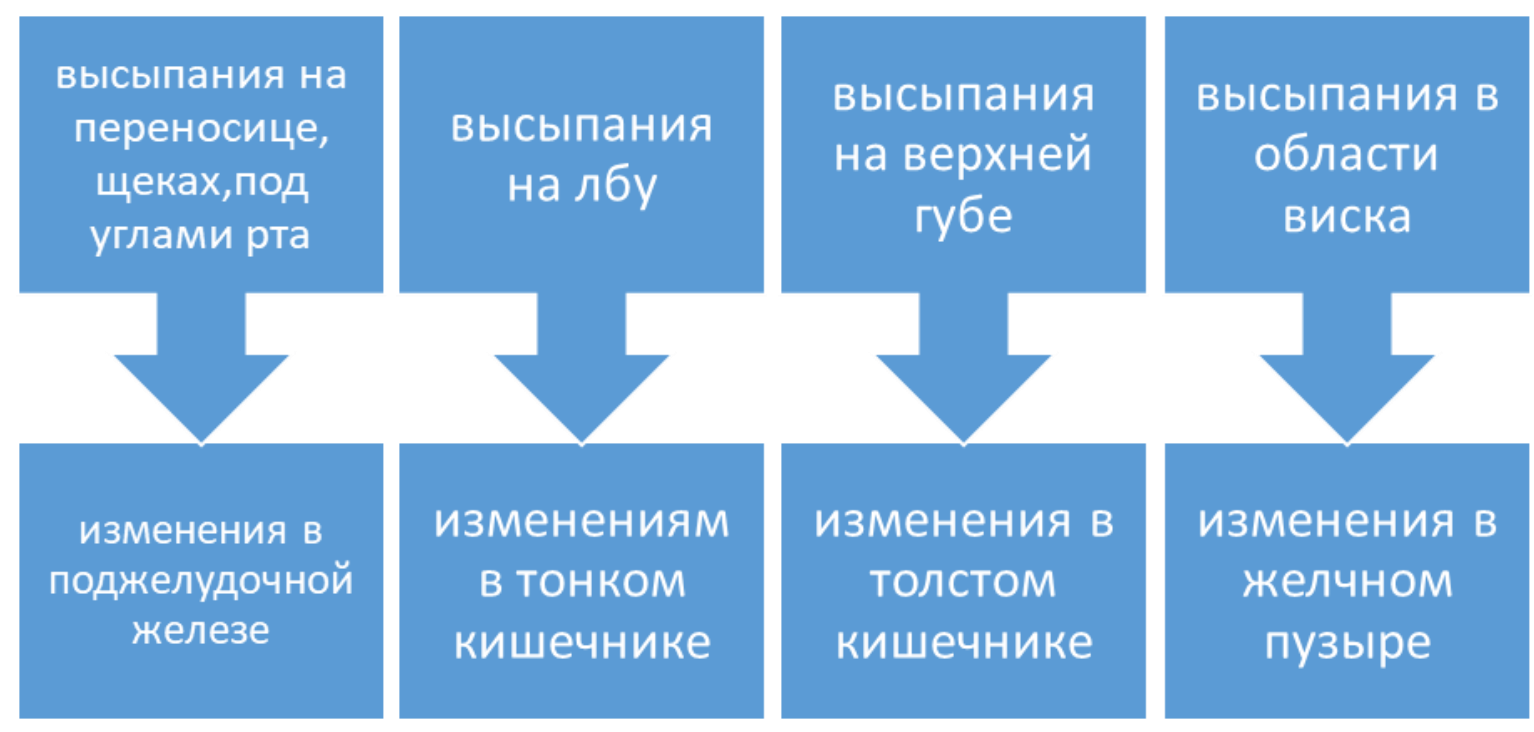

Как в России, так и за рубежом одного мнения у экспертов о влиянии диеты на состояние больных акне нет. Некоторые утверждают, что есть убедительные доказательства того, что диета может усугубить угревую сыпь, а для других исследователей это не так достоверно и доказательно. Эта область весьма противоречива. Есть эксперты, которые полагают, что три основных класса продуктов питания - углеводы, молоко и другие молочные продукты и насыщенные жиры, в том числе транс-жиры, а также дефицит полиненасыщенных омега-3 жирных кислот связаны с появлением и распространением прыщей [2]. Считают, что пациенты должны сбалансировать общее потребление калорий и ограничить молоко, молочные продукты, содержащие лейцин продукты, шоколад, легко усваиваемые углеводы, продукты с 
высоким гликемическим индексом, насыщенные жиры и транс - жиры, белковые добавки. Они рекомендуют диету, обогащенную овощами и рыбой $[3,4]$.

Пациенты с акне чаще всего страдают еще и жирностью кожи, вследствие чего увлажнение, как правило, не требуется, но безмасляный солнцезащитный крем является обязательным требованием, потому что солнечный ожог может вызывать отек эпидермиса и распространение прыщей. Разрешен безмасляный макияж, однако чрезмерные объемы солнцезащитного крема и макияжа будут усугублять прыщи. Запрещено выдавливание прыщей, поскольку это приводит к разрыву фолликула и более сильному узловому воспалению угревой сыпи [6].

В результате исследования «Воронежского государственного медицинского университета им. Н.Н. Бурденко», в котором участвовали 250 учеников 7-11 классов в возрасте от 12 до 16 лет, было выявлено, что:

1) Примерно 25\% исследуемых имели легкую степень тяжести заболевания, а среднюю и тяжелую степень составляли $65 \%$ учеников.

2) $85 \%$ испытуемых либо занимаются самолечением по рекомендации знакомых или фармацевтов в аптеке, многие используют информацию по лечению из рекламных роликов и сайтов в интернете, либо не проводят никакую терапию вообще.

3) $75 \%$ не считают высыпания на коже заболеванием, требующим медицинского вмешательства.

4) За профессиональной помощью обращались только $27 \%$ испытуемых, из которых: к дерматологу - 4\%, к педиатру - 2\%, к дипломированному врачу-косметологу - 9\%, к косметологу в салонах красоты - $12 \%$.

5) У 92\% учащихся имеются комплексы из-за проблемных кожных покровов на лице, шее, спине; они испытывают психоэмоциональный дискомфорт в знакомстве и общении со сверстниками противоположного пола.

6) $98 \%$ исследуемых хотели бы получить профессиональную консультацию и 95\% получить качественное лечение специалиста.

7) $95 \%$ учащихся в качестве профилактики рассматривали личную гигиену, использование косметических средств, правильное питание; 5\% затруднились ответить [7].

\section{Вывод}

Анализ научной литературы показал, что проблема-акне является крайне актуальной, однако подростки мало осведомлены в данной теме. Необходимо проведение консультаций для ознакомления с болезнью, составления диеты правильного питания и соблюдения гигиены.

$$
* * *
$$

1. Бурцева Г. Н., Совершенствование терапии акне на основе клинико-микробиологического исследования. Диссертация, Москва. 2019 год.

2. Melnik B.C. Linking diet to acne metabolomics, inflammation and comedogenesis: Anupdate // Clin Cosmet Investig Dermatol. - 2015. - №8. - P. 371-388

3. Kucharska A, Szmurło A, Sińska B. Significance of diet in treated and untreated acnevlgaris // Postepy Dermatol Alergol. - 2016. - №33 (2). - P. 81-86

4. Альбанова В.И., Новое в диете и медикаментозном лечении акне.// Клиника «Спектра», Москва. Статья в журнале - материалы конференции. Номер: S3 Год: 2018 Cтр. 6

5. Тажимова Л.Я., Мадрахимов Б.С., Современные методы терапии акне и его коррекция с учетом антибиотикорезистентности у больных с угревой болезнью, Ташкентская Медицинская Академия. 2019, № 30 - Стр. 3-8

6. Kurt Gebauer. Acne in adolescents // Australian family physician. - 2017. - №46 (12). - Р. 892-895.

7. Голикова Л.О., Acne vulgaris: превентивные стратегии в России, Германии и других странах/ Л.О.Голикова, В.П. Косолапов, Д.А. Повалюхина// International Journal of Humanities and Natural Sciences, vol. 7-3 (46), 2020 DOI: 10.24411/2500-1000-2020-10805 